American Journal of Biotechemistry and Biotechnology 2 (4): 180-185, 2006

ISSN 1553-3668

(c) 2005 Science Publications

\title{
High Concentrations of Glucose can Activate or Inhibit Human Erythrocyte Aminolevulinate Dehydratase in vitro Depending Exposure Time
}

\author{
Soares, J.C.M., Gabriel, D., Folmer, V., Augusti, G.R. and Rocha, J.B.T. \\ Departamento de Química, Centro de Ciências Naturais e Exatas \\ Universidade Federal de Santa Maria, 97105-900, Santa Maria, RS, Brasil
}

\begin{abstract}
Hyperglycemia can cause oxidative stress and inactivate susceptible enzymes. In the present investigation we examined whether short-term incubations ( 24 or $48 \mathrm{~h}$ ) with high concentrations of glucose (10-200 mmol L-1) inhibit ALA-D from human erythrocytes. Incubations of erythrocytes for $24 \mathrm{~h}$ with glucose (10 up to $\left.40 \mathrm{mmol} \mathrm{\textrm {L } ^ { - }} 1\right)$ resulted in an increase of $\delta$-ALA-D activity $(\mathrm{P}<0,001)$. Incubations of erythrocytes with 100 to $200 \mathrm{mmol} \mathrm{L}^{-} 1$ glucose for $48 \mathrm{~h}$ inhibited $\delta$-ALA-D activity $(\mathrm{P}<0,001)$. DTT $\left(2 \mathrm{mmol} \mathrm{L}^{-} 1\right)$ increased glucose-inhibited $\delta$-ALA-D activity $120 \%$, but the activity did not return to the control level. These results indicated that the inhibitory effect of glucose depends on time of exposure and its concentration. A significant positive correlation was found between $\delta$ ALA-D activity and NPSH groups from erythrocytes incubated 24h with different glucose concentrations. $(\mathrm{r}=0.65, \mathrm{P}<0.0001$. In contrast to the results of $24 \mathrm{~h}$, incubation of erythrocytes for $48 \mathrm{~h}$ with 100,150 and $200 \mathrm{mmol} \mathrm{L}^{-} 1$ of glucose did not modify significantly the NPSH content from erythrocytes. Incubations of erythrocytes for $48 \mathrm{~h}$ with increasing concentrations of glucose (100 to $200 \mathrm{mmol} \mathrm{L}^{-} 1$ ) resulted in a significant concentration-dependent increase of TBARS content compared with control group. The TBARS content of erythrocytes incubated for $24 \mathrm{~h}$ with 5 (control), 10, 20, 30, 40 and $100 \mathrm{mmol} \mathrm{L}^{-} 1$ of glucose tend to increase as the concentration of glucose increased; however, the values were significantly higher than control only after incubation with 30,40 and $100 \mathrm{mmol} \mathrm{L}^{-1}$ of glucose. The results of this study indicate that the use of high concentrations of glucose (above $30 \mathrm{mmol} \mathrm{L}^{-} 1$ ) for short periods is of little pathophysiological significance for the study of molecular mechanism underlining enzymes inhibition caused by glucose. Thus, further in vitro studies (using glucose concentrations lower than $30 \mathrm{mmol} \mathrm{L}^{-} 1$ for higher periods of cells exposure to glucose) are necessary to established whether or not in vitro incubation of erythrocytes with glucose can be considered a reliable model for the study of the toxicity of glucose to proteins under pathophysiological conditions.
\end{abstract}

Key words: Ebselen, sugar reducing, $\delta$-aminolevulinate dehydratase ( $\delta$-ALA-D), oxidative stress

\section{INTRODUCTION}

Diabetic state is associated with increased oxidative stress and hyperglycemia is an important factor which facilitates overproduction of oxygen free radicals ${ }^{[1-17]}$. Pro-oxidative state can produce permanent chemical alterations in proteins and increase lipid peroxidation in a variety of models of hyperglycemia ${ }^{[17,18]}$. Exposure of macromolecules in vitro to glucose concentrations representative of hyperglycemia is considered a relevant model for studying the functional degenerations occurring in diabetes mellitus ${ }^{[13]}$. In line with this, the deleterious effects of hyperglycemia on the properties of physiologically abundant proteins such as hemoglobin, albumin and collagen have been extensively investigated ${ }^{[16]}$. Nonenzymatic glycation is the first of a series of reactions caused by hyperglycemia and this process can promote in vivo and in vitro cross-linking of proteins ${ }^{[6,19]}$.

$\delta$-Aminolevulinate dehydratase ( $\delta$-ALA-D) is an essential enzyme for aerobic organisms because participates in the biosynthesis pathway of tetrapyrrole molecules, which constitute prosthetic groups of physiologically significant proteins such as hemoglobin and cytochromes ${ }^{[20,21]}$. This enzyme seems to be a good marker for oxidative stress due to its sulfhydryl nature, which renders the enzyme highly sensitive to the presence of pro-oxidant situations ${ }^{[8-10,22-25]}$. Of particular importance, the heme synthetic pathway is impaired in porphyria and a frequent coexistence of diabetes mellitus and porphyria disease has been reported in humans and experimental animal models ${ }^{[26,27]}$, which can be linked to inhibition of this enzyme found in diabetics ${ }^{[28,29]}$.

Corresponding Author: João Batista Teixeira Rocha, Departamento de Química, Centro de Ciências Naturais e Exatas, Universidade Federal de Santa Maria, 97105-900, Santa Maria, RS, Brasil, Tel: 021-55 220-8140, Fax: 021-55-220-8031 
The aim of this study was to investigate in vitro the effect of high concentrations of glucose on $\delta$-ALA-D activity and whether the activity of enzyme could be correlated with TBARS production and with nonprotein -SH content from human erythrocytes. Although high concentrations of glucose represents an artificial situation and indicates a limitation of such sort of study, it has the advantage of providing rapid results that can guide further molecular approaches to investigate the role of hyperglycemia in the development of pathological complications of diabetes.

\section{MATERIALS AND METHODS}

Compounds: 5-aminolevulinic acid, DL-dithiothreitol and malondialdehyde (MDA) were obtained from Sigma (St. Louis, MO., USA). Mono- and dibasic potassium phosphate, acetic acid, ortho-phosphoric acid, tris buffer (tris[hydroxymethyl]aminomethane), glucose, hydrogen chloride, trichloroacetic acid and sodium chloride were obtained from Merck (Rio de Janeiro, Brazil).

Blood sample collection: Blood samples from 20 healthy donors $(10 \mathrm{~mL}$ each) were drawn in the fasting state and processed within $1 \mathrm{~h}$ of collection. Samples were transferred to sterile polypropylene tubes containing herparin. For in vitro experiments the samples were centrifuged for $10 \mathrm{~min}$ at $1,500 \mathrm{~g}$ and erythrocytes were washed three times with $\mathrm{NaCl} 0.9 \%$ and were suspended with $\mathrm{NaCl} 0,9 \%$ taking hematocrit $50 \%$ (1:1). Tubes containing $1.5 \mathrm{~mL}$ of cell suspension were incubated with different glucose concentrations at $37^{\circ} \mathrm{C}$ for 24 or $48 \mathrm{~h}$. The incubation mixtures contained $10 \mathrm{mmol} \mathrm{L}{ }^{-1}$ Tris $\mathrm{HCl}(\mathrm{pH} \quad 7,4)$ and $400 \mu \mathrm{g}$ Gentamicin. The osmolarity of the solutions were adjusted to $300 \mathrm{mOsm}$ by adding different concentrations of $\mathrm{NaCl}$.

Biochemical assays: $\delta$-ALA-D activity was assayed by the method of Sassa et al. ${ }^{[30]}$ by measuring the rate of product (porphobilinogen) formation except that 84 mmol L-1 potassium phosphate buffer, $\mathrm{pH} 6.4$ and 2.4 mmol L${ }^{-} 1$ ALA were used. The reaction was started 10 min after the addition of the enzyme preparation by adding the substrate. Incubations were carried out for $1 \mathrm{~h}$ at $37^{\circ} \mathrm{C}$. The reaction product was determined using modified Ehrlich's reagent at $555 \mathrm{~nm}$, with a molar absorption coefficient of $6.1 \times 10^{4} \mathrm{M}^{-1}$ for the Ehrlichporphobilinogen salt. The reaction rates were linear with respect to time of incubation and added protein for all experimental conditions.

Thiobarbituric acid reactive species assay: Thiobarbituric acid reactive species (TBA-RS) were determined according to Ohkawa et al. ${ }^{[31]}$, with few modifications. Blood was precipitated with one volume of TCA $(40 \%)$ and left on ice for $30 \mathrm{~min}$ before centrifugation. TBARS were quantified by adding 1000 $\mu \mathrm{l}$ of the supernatant fractions to the color reaction medium. The amount of TBA-RS produced was measured at $532 \mathrm{~nm}$, using MDA to construct standard curves.

Determination of erythrocytes sulfhydryl status: Erythrocyte non-protein sulfhydryl groups were determined using Ellman's reagent, 5,5'-dithiobis(2nitrobenzoate) with few modifications. Blood was precipitated with 1 volume of 5\% TCA. After centrifugation, the supernatant was neutralized with Tris- $\mathrm{NaOH}$ and non-protein sulfhydryl groups (NPSH) were quantified on these supernatant fractions. The sulfhydryl concentration was calculated against a standard curve of cysteine ${ }^{[32]}$.

Statistical analysis: Results are expressed as means \pm SEM. The results were evaluated by ANOVA (SPSS for Windows 8.0, SPSS 1998, Chicago, IL). When the ANOVA was significant, differences between groups were determined using Duncan's Multiple Range test (SPSS for Windows 8.0, SPSS 1998, Chicago, IL). Correlation coefficients were determined by linear regression analysis. Differences between groups were considered to be significant when $\mathrm{P}<0.05$.

\section{RESULTS}

Incubations of erythrocytes for $24 \mathrm{~h}$ with increasing concentrations of glucose (10 up to $40 \mathrm{mmol}$ $\left.\mathrm{L}^{-} 1\right)$ in a significant increase of $\delta$-ALA-D activity $\left(\mathrm{P}<0,001\right.$; Fig. 1). In the presence of $100 \mathrm{mmol} \mathrm{L}^{-1}$ glucose, enzyme activity return to control level. In contrast, incubations of erythrocytes with 100 to 200 mmol L ${ }^{-1}$ glucose for $48 \mathrm{~h}$ inhibited $\delta$-ALA-D activity, when compared with erythrocytes of control group (incubated with glucose $\left.5 \mathrm{mmol} \mathrm{L}^{-1} 1\right) \quad(\mathrm{P}<0,001)$. Involvement of cysteinyl groups in $\delta$-ALA-D inhibition caused by $48 \mathrm{~h}$ exposure to glucose was examined by testing the possible restoration effect of dithiothreitol (DTT) on this enzyme. Addition of DTT ( $\left.2 \mathrm{mmol} \mathrm{L}^{-} 1\right)$ in the assay mixture increased $\delta$-ALA-D activity about $120 \%$, but the activity did not return to the control level (Fig. 2). Taken together, these results indicate that the inhibitory effect of glucose depends on time of exposure and its concentration.

Since reduced cysteinyl residues are essential to $\delta$ ALA-D, we realized that the changes in erythrocyte $\delta$ ALA-D activity could be related to changes in the levels of non-protein -SH (NPSH). To test this hypothesis we determined the NPSH content after incubations of erythrocytes with different concentrations of glucose. NPSH content from erythrocytes incubated for $24 \mathrm{~h}$ increased significantly as the concentration of glucose increased from 5 to 30 mmol L${ }^{-} 1$. Thereafter, NPSH tended to return to control 


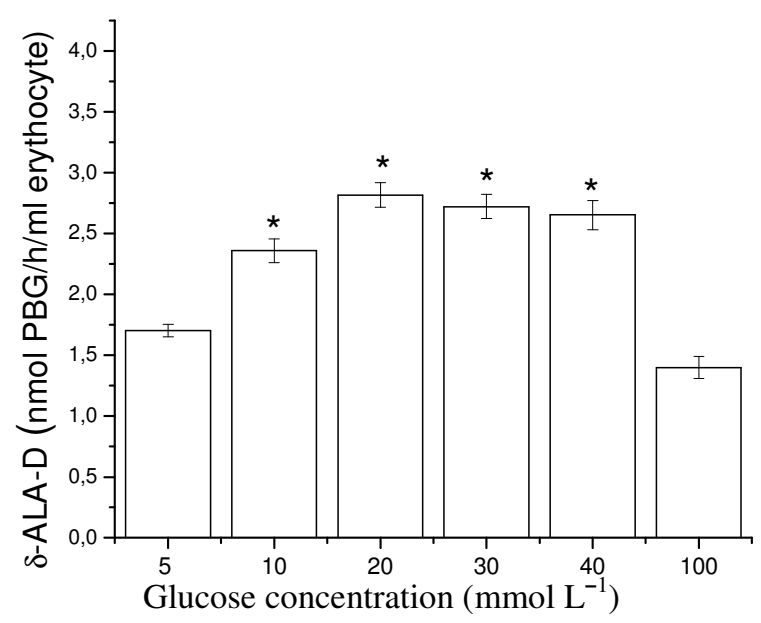

Fig. 1: $\delta$-ALA-D activity in erythrocytes incubated for $24 \mathrm{~h}$ with glucose (5 to $100 \mathrm{mmol} \mathrm{\textrm {L } ^ { - }} 1$ ). Erythrocytes were incubated at $37^{\circ} \mathrm{C}$. Results are expressed as means \pm S.D. for six sample per group $(\mathrm{P}<0.001)$

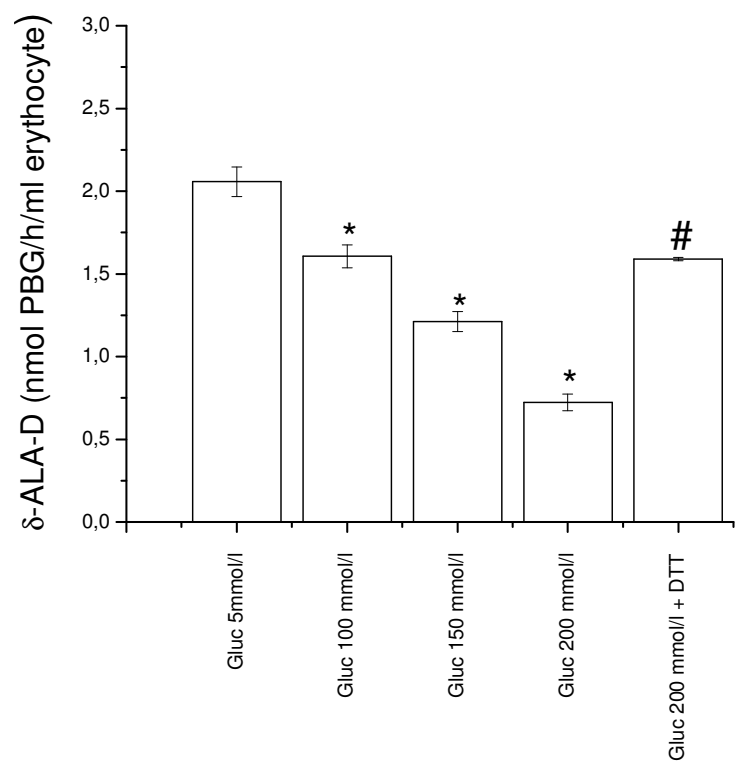

Fig. 2: $\delta$-ALA-D activity in erythrocytes incubated for $48 \mathrm{~h}$ with glucose ( 5 to $200 \mathrm{mmol} \mathrm{L}^{-} 1$ ). After the pre-incubation of $48 \mathrm{~h}$ ALA-D from erythrocytes was determined either in the absence or the presence of $2 \mathrm{mmol} \mathrm{L}^{-} 1$ DTT. Erythrocytes were incubated at $37^{\circ} \mathrm{C}$. Results are expressed as means \pm S.D. for ten samples per group $(* P$ $<0.001$; $\#$ P $<0.001$ )

levels (Fig. 3). A statistically significant positive correlation was found between $\delta$-ALA-D Activity and NPSH groups from erythrocytes incubated $24 \mathrm{~h}$ with different glucose concentrations. $(\mathrm{r}=0.65, \mathrm{P}<0.0001$; Fig. 4). In contrast to the results of $24 \mathrm{~h}$, incubation of erythrocytes for $48 \mathrm{~h}$ with 100,150 and $200 \mathrm{mmol} \mathrm{L}^{-} 1$ of glucose did not modify significantly the NPSH content from erythrocytes (Fig. 5).

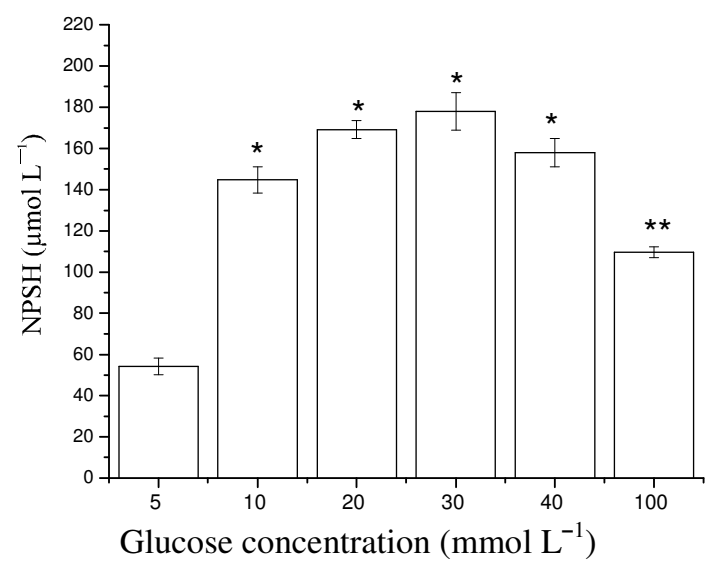

Fig. 3: Non-protein thiol groups (NPSH) from erythrocytes incubated $24 \mathrm{~h}$ at $37^{\circ} \mathrm{C}$ with different concentrations of glucose. Data are expressed as mean \pm SEM for 6 samples per group. $\left({ }^{*} \mathrm{P}<0.001 ; * * \mathrm{P}<0.01\right)$

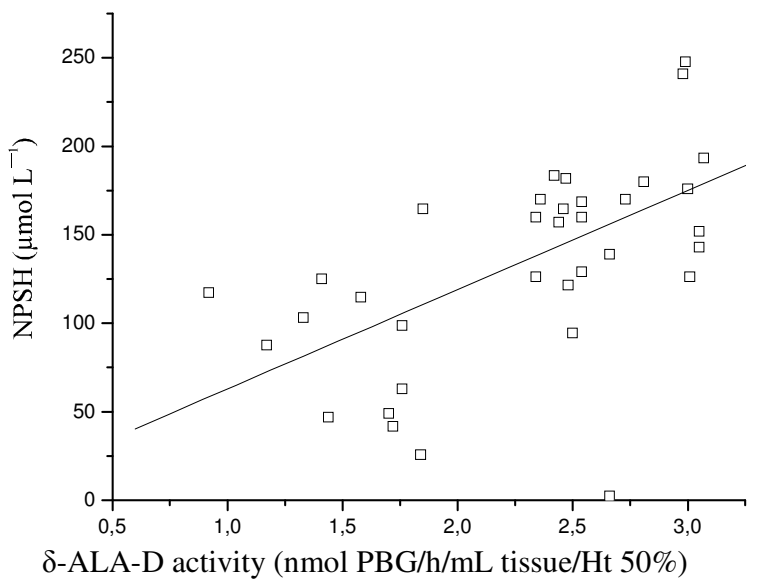

Fig. 4:Correlation between $\delta$-ALA-D activity and NPSH from erythrocytes incubated 24h with different glucose concentrations. Data are expressed as mean \pm SEM for 6 samples per glucose concentration $(\mathrm{r}=0.65, \mathrm{P}<0.0001)$

Incubations of erythrocytes for $48 \mathrm{~h}$ with increasing concentrations of glucose (100 to $200 \mathrm{mmol} \mathrm{L}^{-} 1$ ) resulted in a significant concentration-dependent increase of TBA-RS content compared with control group (Fig. 6). The TBA-RS content of erythrocytes incubated for $24 \mathrm{~h}$ with 5 (control), 10, 20, 30, 40 and $100 \mathrm{mmol} \mathrm{L}^{-} 1$ of glucose tend to increase as the concentration of glucose increased; however, the values were significantly higher than control only after incubation with 30,40 and $100 \mathrm{mmol} \mathrm{L}^{-1}$ of glucose (data not shown).

\section{DISCUSSION}

Glycosilation of protein play a significant role in protein aging ${ }^{[7,13,33]}$ and this reaction starts with the 


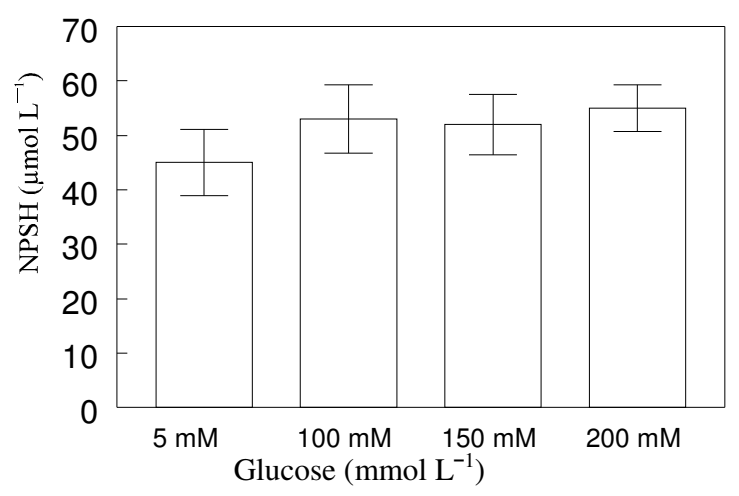

Fig. 5: Non-protein thiol groups (NPSH) from erythrocytes incubated $24 \mathrm{~h}$ at $37^{\circ} \mathrm{C}$ with different concentrations of glucose. Data are expressed as mean \pm SEM for 5 samples per group. $(* \mathrm{P}<0.001 ; * * \mathrm{P}<0.01)$

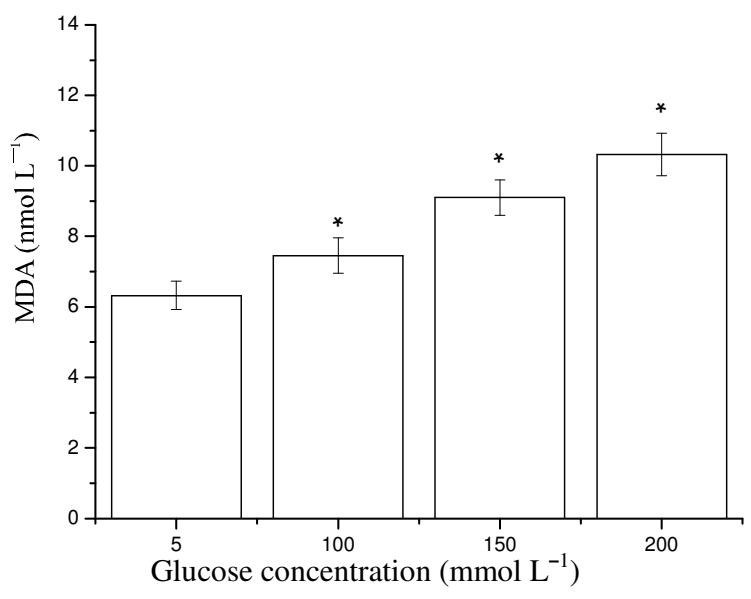

Fig. 6:TBARS content in erythrocytes incubated for $48 \mathrm{~h}$ at $37^{\circ} \mathrm{C}$ with glucose in the concentrations of $5 \mathrm{mmol} \mathrm{L}^{-1}$ up to $200 \mathrm{mmol} \mathrm{\textrm {L } ^ { - }}$. Data are expressed as mean \pm SEM for 8 samples per group. $*(\mathrm{P}<0.001)$

reversible formation of a Shiff base between glucose and protein amino groups. Hyperglycemia can increase the production of reactive oxygen species, which contribute to cause permanent chemical alterations in proteins. In the present study, we showed that the exposure for $24 \mathrm{~h}$ to high concentrations of glucose (up to $40 \mathrm{mmol} \mathrm{L}^{-} 1$ ), contrary to our expectancy, caused a significant increase in $\delta$-ALA-D activity of erythrocytes. Probably, this was a consequence of production of low-molecular-SH containing molecules (glutathaione) derived from reducing equivalents of NADPH formed in the pentose pathway. In fact, we found a positive correlation between ALA-D activity and NPSH groups in erythrocytes incubated for $24 \mathrm{~h}$ with glucose. The protecting effect of glucose decreased when the blood was incubated with 100 mmol $\mathrm{L}^{-} 1$ of glucose. The decrease in NPSH can be due to the fact that elevated extra and intracellular glucose concentrations stimulate the polyol pathway, which depletes the intracellular NADPH levels ${ }^{[5,34,35]}$.

In addition, the decrease can be also a consequence of elevated production of free radicals, that was confirmed by an increase in erythrocyte TBARS. The formed radicals could interact either directly or indirectly with thiols, oxidizing them to disulfides ${ }^{[36-40]}$. In any case, the present results clearly indicate that care must be taken when using short-term in vitro experiments with high concentrations of glucose. The stimulation of $\delta$-ALA-D by pathologically relevant concentrations of glucose $(10-30 \mathrm{mmol} \mathrm{L}-1)$ possibly has no in vivo significance. In fact, data from our laboratory and other suggest that in vivo hyperglycemia is associated with $\delta$-ALA-D inhibition ${ }^{[8,10,28,29]}$.

In contrast to the results of $24 \mathrm{~h}$, exposure of erythrocytes for $48 \mathrm{~h}$ to non-physiological concentrations of glucose (100 to $200 \mathrm{mmol} \mathrm{L}^{-} 1$ ) caused $\delta$-ALA-D inhibition that was partially reversed by DTT. These results strongly suggest that cysteinyl residues of $\delta$-ALA-D are involved in the enzyme inhibition caused by high concentrations of glucose. These results are in sharp contrast with our laboratories studies showing that enzyme thiols are not involved in the inhibition of $\delta$-ALA-D after very short-term (up to $1 \mathrm{~h})$ periods of exposure to extremely high concentrations of reducing sugars ${ }^{[41]}$. The molecular mechanism underlying $\delta$-ALA -D impairment in diabetes is still not completely understood, but may be caused either by glycation of the active site lysine residue involved in Schiff's base formation with the first $\delta$-ALA molecule or oxidation of essential reduced cysteinyl residues of the enzyme ${ }^{[8,10,19]}$. Over production of free radicals could be also contributing to the formation of adducts between the aldehyde group of glucose and the amino group of lysine in $\delta$-ALA-D. Taken together, these results may indicate that glucose inhibit the enzyme activity by two distinct mechanisms: 1) one involving the oxidation of cysteinyl residues and 2) another involving a formation of an intermediate between glucose and the lysil residue at the active site of the enzyme. Probably the oxidation of cysteinyl residues was mediated by glucose autoxidation and free radical production.

In conclusion, the results of the present investigation indicate that use of relatively high concentrations of glucose (above $30 \mathrm{mmol} \mathrm{L}^{-} 1$, which corresponds to $540 \mathrm{mg} \%$ glucose and a blood concentration rarely found in treated diabetes) for short periods of exposition are of little pathophysiological significance for the study of molecular mechanism underlining enzymes inhibition caused by glucose. These results also indicate that authors must be careful in extrapolating in vitro findings to in vivo situations, fact that has occurred in the literature ${ }^{[18,42]}$. Thus, although in vitro models can guide in vivo studies, 
further and more detailed in vitro studies (using lower glucose concentrations than $30 \mathrm{mmol} \mathrm{L}^{-} 1$ with higher periods of cells exposure to glucose) are necessary to established whether or not in vitro incubation of erythrocytes with glucose can be considered a reliable model for the study of the toxicity of glucose to proteins under pathophysiological conditions.

\section{REFERENCES}

1. Allen, D.A., S. Harwood, M. Varagunam, M.J. Raftery and M.M Yaqoob, 2003. High glucoseinduced oxidative stress causes apoptosis in proximal tubular epithelial cells and is mediated by multiple caspases. Faseb. J., 17: 908-911.

2. Revsin, Y., Saravia, F., Roig, P., Lima, A., de Kloet, E.R., Homo-Delarche, F., De Nicola, A.F., 2005. Neuronal and astroglial alterations in the hippocampus of a mouse model for type 1 diabetes. Brain Res., 1038: 22-31.

3. Aydýn, A., H. Orhan, A. Sayala, M. Ozata, G. Sahim and A. Isymer, 2001. Oxidative stress and nitric oxide related parameters in type ii diabetes mellitus: Effects of glycemic control. Clin. Biochem., 34: 65-70.

4. Kutlu, M., Naziroglu, M., Simsek, H., Yilmaz, T., Kukner, A.A., 2005. Moderate exercise combined with dietary vitamins $\mathrm{C}$ and $\mathrm{E}$ counteracts oxidative stress in the kidney and lens of streptozotocin-induced diabetic rat. Int. J. Vit. Nut. Res., 75: 71-80.

5. Bonnefont-Rousselot, D., J.P. Bastard, M.B. Jaudon and J. Delattre, 2000. Consequences of the diabetic status on the oxidant/antioxidant balance. Diabetes Metabol., 26: 163-176.

6. Rojas, A. and M.A. Morales, 2004. Advanced glycation and endothelial functions: A link towards vascular complications in diabetes. Life Sci., 76: 715-730.

7. Hsu, C.C., H.F. Yen, M.C. Yin, C.M. Tsai and C.H. Hsieh, 2004. Five cysteine-containing compounds delay diabetic deterioration in Balb/cA mice. J. Nut., 134: 3245-3249.

8. Folmer, V., J.C.M. Soares and J.B.T. Rocha, 2002. Oxidative stress in mice is dependent on the free glucose content of the diet. The Intl. J. Biochem. \& Cell Biol., 34: 1279-1285.

9. Folmer, V., F.W. Santos, L. Savegnago, V.B. Brito, C.W. Nogueira and J.B.T. Rocha, 2004. High sucrose consumption potentiates the subacute cadmium effect on $\mathrm{Na} / \mathrm{K}+$-ATPase but not on Delta-Aminolevulinate Dehydratase in mice. Toxicol. Lett., 153: 333-341.

10. Folmer, V., J.C.M. Soares, D. Gabriel and J.B.T. Rocha, 2003. High-fat diet causes $\delta$ aminolevulinate dehydratase inhibition and hemoglobin glycation related to lipid peroxidation in mice. J. Nut., 133: 2165-2170.
11. Fu, M.X, K.J. Knecht, S.R. Thorpe and J.W. Baynes, 1992. Role of oxygen in crosslinking and chemical modification of collagen by glucose. Diabetes, 41: 42-48.

12. Hans, H.P, X. Du, D. Edelstein, T. Taguchi, T. Matsumura, Q. Ju, J. Lin, A. Bierhaus, P. Nawroth, D. Hannak, M. Neumaier, R. Bergfeld, I. Giardino and M. Brownlee, 2003. Benfotiamine blocks three major pathways of hyperglycemic damage and prevents experimental diabetic retinopathy. Nat. Med., 9: 294-299.

13. Hunt, J.V, R.T. Dean and S.P. Wolff, 1998. Hydroxyl radical production and autoxidative glycosylation. Biochem. J., 256: 205-212.

14. Nakamura, Y., Q. Feng, T. Kumagai, K. Torikai, H. Ohigashi, T. Osawa, N. Noguchi, E. Niki and K. Uchida, 2002. Ebselen, a glutathione peroxidase mimetic seleno-organic compound, as a multifunctional antioxidant. The J. Biol. Chem., 277: 2687-2694.

15. Vincent, A.M., J.W. Russell, P. Low and E.L. Feldman, 2004. Oxidative stress in the pathogenesis of diabetic neuropathy. Endoc. Rev., 25: 612-628.

16. Schwartz, J.G., 1995. The role of glycohemoglobin and other proteins in diabetes management. Diabetes Rev., 3: 269-287.

17. Wolff, S.P. and R.T. Dean, 1987. Glucose autoxidation and protein modification. The potential Role of 'Autoxidative Glycosylation' in Diabetes. Biochem. J., 245: 243-250.

18. Jain, S.K. and G. Lim, 2001. Pyridoxine and pyridoxamine inhibits superoxide radicals and prevents lipid peroxidation, protein glycosylation and $\left(\mathrm{Na}^{+} / \mathrm{K}^{+}\right)$-ATPase activity reduction in high glucose-treated humam erythrocytes. Free Rad. Biol. \& Med., 30: 232-237.

19. Caballero, F.A., E.N. Gerez, C.F. Polo, E.S. Vasquez and A.M.C. Batlle, 1998. Reducing sugar trigger $\delta$-aminolevulinate dehydratase inactivation: Evidence in vitro aspirin prevention. Gen. PharmacoI., 31: 441-445.

20. Jaffe, E.K., S. Ali, L.W. Mitchell, K.M. Taylor, M. Volin and G.D. Markham, 1995. Characterization of the role of the stimulatory magnesium of Escherichia coli porphobilinogen synthase. Biochemistry, 34: 244-251.

21. Sassa, S., 1998. ALAD porphyria. Seminars in Liver Disease, 18: 95-101.

22. Folmer, V., R.C. Bolzan, M. Farina, G. Zeni, C.W. Nogueira, T. Emanuelli and J.B.T. Rocha, 2005. Mechanism of delta-aminolevulinate dehydratase inhibition by phenyl selenoacetylene involves its conversion to diphenyl diselenide. Toxicology, 206: 403-411.

23. Soares, J.C.M., V. Folmer and J.B.T. Rocha, 2002. Influence of dietary selenium supplementation and exercise on thiol-containing enzymes in mice. Nutrition, 19: 627-632. 
24. Nogueira, C.W., G. Zeni and J.B.T. Rocha, 2004. Organoselenium and organotellurium compounds: toxicology and pharmacology. Chem. Rev., 104: 6255-6285.

25. Rocha, J.B.T., S.M. Tuerlinckx, M.R.C. Schetinger and V. Folmer, 2004. Effect of group 13 metals on porphobilinogen synthase in vitro. Toxicol. Appl. Pharmacol., 200: 169-176.

26. Bitar, M. and M. Weiner, 1984. Diabetes-induced metabolic alterations in heme synthesis and degradation and various heme-containing enzymes in female rats. Diabetes, 33: 37-44.

27. Scassa, M.E., C.L. Varone, L. Montero and E.T. Cánepa, 1998. Insulin inhibits $\delta$-aminolevulinate synthase gene expression in rat hepatocytes and human hepatoma Cells. Exp. Cell. Res., 244: 460469.

28. Caballero, F., E. Gerez, C. Polo, O. Mompo, E. Vazquez, R. Schultz, J. Bernabé and A. Batlle, 1995. Alteraciones en el Camino Metabolico del Hemo en Pacientes Diabeticos. Medicina, 55: 117124.

29. Fernández-Cuartero, B., J.L. Rebollar, A. Batlle and R.E. Salamanca, 1999. Delta aminolevulinate dehydratase (ALA-D) activity in human and experimental diabetes mellitus. Intl. J. Biochem. Cell Biol., 31: 479-488.

30. Sassa, S., 1982. Delta-aminolevulinic acid dehydratase assay. Enzyme, 28:133-145.

31. Ohkawa, H., N. Ohishi and K. Yagi, 1979. Assay for lipid peroxides in animal tissues by thiobarbituric acid reaction. Anal. Biochem., 95: 351-358.

32. Ellman, G.L., 1959. Tissue sulphydril groups. Arch. Biochem. Biophys., 82: 70-77.

33. Carubelli R., J. Schineider, Q. Pye and R. Floyd, 1994. Citotoxic effects of autoxidative glycation. Free Radic Biol Mol., 18: 265-269.
34. Nakamura, J., N. Koh, F.S. Sakakibara and Y. Hamada, 1995. Polyol pathway, 2,3 diphophoglycerate in erythrocytes and diabetic neuropathiy in rats. Eur. J. Pharm., 294: 207-214.

35. Jozwik, M., M. Jozwik, M. Jozwik, M. Szczypka, J. Gajewska and J. Laskowska-Klita, 1997. Antioxidant defence of red blood cells and plasma in stored human blood. Clin. Chim. Acta, 267: 129142.

36. Misra, H.P. Generation of superoxide free radical during the autoxidation of thiols. The J. Biol. Chem., 249: 2151-2155.

37. Radi, R., J.S. Bechman, K.M. Bush and B.A. Freeman, 1991. Peroxynitrite oxidation of sulfhydryl. J. Biol. Chem., 266: 4244-4250.

38. Bourdon, E., N. Loreau and D. Blache, 1999. Glucose and free radicals impair the antioxidant properties of serum albumin. FASEB J., 13: 233244.

39. Dean, R.T., S. Fu, R. Stocker and M.J. Davies, 1997. Biochemistry and pathology of radicalmediated protein oxidation. Biochem. J., 324: 1-18.

40. Carty, J.L., R. Bevan, H. Waller, N. Mistry, M. Cooke, J. Lunec and H.R. Griffiths, 2000. The effects of vitamin $\mathrm{C}$ supplementation on protein oxidation in healthy volunteers. Biochem. Biophys. Res. Com., 273: 729-735.

41. Gabriel, D., L. Pivetta, V. Folmer, J.C. Soares, G.R. Augusti, C.W. Nogueira, G. Zeni and J.B.T. Rocha, 2005. Human erythrocyte deltaaminolevulinate dehydratase inhibition by monosaccharides is not mediated by oxidation of enzyme sulfhydryl groups. Cell Biol Intl. (in press).

42. Jain, S.K. and G. Lim, 2000. Lipoic acid decreases lipid peroxidation and protein glycosylation and increases $\left(\mathrm{Na}^{+}+\mathrm{K}^{+}\right)$- and $\mathrm{Ca}^{++}$-ATPase activities in high glucose-treated human erythrocytes. Free Rad. Biol. Med., 29: 1122-1128. 